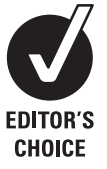
Dr D J Pevalin, School of Health and Human Sciences, University of Essex, Colchester, CO4 3SQ; pevalin@essex.ac.uk

Accepted 6 May 2009 Published Online First

2 July 2009

\title{
Housing repossessions, evictions and common mental illness in the UK: results from a household panel study
}

\author{
D J Pevalin
}

\begin{abstract}
Background: The numbers of housing repossessions and evictions in the UK are increasing. This study investigates whether repossessions and evictions increase the likelihood of common mental illness and examine patterns over time.

Methods: Data come from the core longitudinal panel of the British Household Panel Survey ( $N=12$ 390) of adults living in private households. Multivariate fixedeffects regression models are used with weighted data. Common mental illness is measured by the 12-item General Health Questionnaire.
\end{abstract}

Results: Housing repossession is associated with an increased risk of common mental illness (adjusted odds ratio $1.61,95 \%$ confidence interval 1.10 to 2.36 ), whereas eviction from rented property shows no increased risk $(0.97,0.76$ to 1.20$)$. The pattern over time shows a clear increase in the years before repossession.

Conclusions: Repossession of owned property, although a relatively rare event in the panel, significantly increases the risk of common mental illness immediately after the event. In contrast, eviction from rented property is a more common event but is not associated with an increased risk of common mental illness. This difference in association may be due to losing the security of owned housing and the often transitory nature of the rented housing population.

Since 1991, there have been more than half a million repossessions and more than one million eviction orders made on behalf of social and private landlords. ${ }^{1}$ The current economic situation, particularly the reduction in the availability of credit, has led to increased financial pressures on home owners. However, the majority of research on housing eviction has been conducted in the developing world around the issue of land appropriation, with some notable exceptions in The Netherlands, ${ }^{2}$ Sweden, ${ }^{3}$ the USA, ${ }^{4-6}$ and research on older populations. ${ }^{7}$ The characteristics of housing repossession in the UK are distinct from other European nations due to the cost of housing, the high housing cost/income proportion and decline in the supply of social housing, all of which makes it more difficult to recover from a repossession and get another form of housing. The deleterious effects of unsustainable financial commitments for housing on mental health have been documented and for a significant minority this results in repossession or eviction. ${ }^{8-10}$ Housing tenure has a long-established association with psychological well-being, but this study examines the effects of compulsory changes to housing tenure through repossession or eviction. ${ }^{11-14}$

\section{METHODS}

Data came from 17 annual waves of the British Household Panel Survey (BHPS), which started in 1991 and later added booster samples for Scotland, Wales and Northern Ireland. The BHPS is a wellestablished survey that is extensively documented elsewhere. ${ }^{15}{ }^{16}$ Overall, the panel was unbalanced as individuals move in and out of the study according to a set of following rules. This analysis used the core longitudinal panel of respondents who have been in the survey at all eligible time points and whose data are weighted for selection and attrition ( $N=12$ 390; person/years 139 928). Ethics approval was granted by University of Essex process for secondary data analysis of survey data.

Common mental illness was measured by the 12-item General Health Questionnaire (GHO). Items were coded to make a 0-12 scale, then a threshold of 4 or more was used to indicate common mental illness. ${ }^{17-20}$

Respondents who had moved since their last interview were asked why they had moved. One of the possible responses was "repossession or eviction". This was used with their housing tenure from the previous interview to create a time varying indicator, so that those who were home owners are designated as having experienced repossession and those who were renters are designated as having experienced an eviction.

Social class, marital status, age and employment status were used in the analysis as potential time varying confounders, as these have well-documented associations with common mental illness. All time constant characteristics were controlled for in fixed-effect models.

Descriptive statistics illustrate the proportions of those with common mental illness in the years before and after repossession or eviction. These were compared with norms for the respective groups for the panel sample and presented graphically.

Two multivariate fixed-effects logit regression models, one for repossessions and one for evictions, were used to estimate the net effect of the change in housing status on the risk of common mental illness, with estimating samples limited to those at risk of such an event: home owners $(\mathrm{N}=9768$; person/years $=83129)$ and renters $(N=3899$; person/years $=22744)$ respectively. Respondents who were owners and renters over the time of the panel were included in both models, but only 
for the years they were at risk of a repossession or eviction. Fixed-effects regression methods control for all stable characteristics of the individuals, whether measured or not, by using only within-individual variation to estimate the regression coefficients, so respondents must be observed at least twice to be included in the estimations. ${ }^{21}$

(1) $\operatorname{Pr}\left(y_{i t}=1 \mid X_{i t}, C_{i t}\right)=F\left(\alpha X_{i t}+\beta C_{i t}\right)$ if housing tenure $e_{t-1}$ $=$ owner

(2) $\operatorname{Pr}\left(\mathrm{y}_{\mathrm{it}}=1 \mid \mathrm{X}_{\mathrm{it}}, \mathrm{C}_{\mathrm{it}}\right)=\mathrm{F}\left(\alpha \mathrm{X}_{\mathrm{it}}+\beta \mathrm{C}_{\mathrm{it}}\right)$ if housing tenure $\mathrm{t}_{\mathrm{t}-1}$ $=$ renter

Where $y$ is the dichotomous GHO indicator of individual $i$ at time $t ; F$ is the cumulative logistic function; $X_{i t}$ is the time varying repossession (equation 1) or eviction (equation 2) indicator; $\mathrm{C}_{i t}$ is a vector of time varying confounders; $\alpha$ and $\beta$ are parameters to be estimated. The value of $\alpha$ is given as adjusted odds ratios (OR) with robust $95 \%$ confidence intervals (CI) ${ }^{22}$

\section{RESULTS}

There were a total of 145 (weighted: 220) repossessions and 493 (weighted: 838) evictions. Figure 1 presents the proportions of those experiencing repossession (squares) or an eviction (diamonds) with common mental illness for two observations before the event and three observations after the event. The total sample proportions for owners and renters are also shown for comparison. Those who experience repossession show an increase before and immediately after the event with large changes after that; possibly due to the small number of events. Proportions at all time points are well above the sample proportion for owners. Those who are evicted show a slight increase before the event but then a steady decline after the event, but never far from the overall sample proportion for renters.

The regression models estimate that at time $t$ those who experienced repossession are significantly more likely to report common mental illness (OR 1.61, 95\% CI 1.10 to 2.36), whereas eviction from rented property shows no increased risk (OR 0.97, $95 \%$ CI 0.76 to 1.20 )

\section{DISCUSSION}

Repossession significantly increases the risk of poor mental health and the pattern over time suggests that the lead up to repossession also has a detrimental effect. Post repossession, the proportion with common mental illness varies widely. Evictions from rented housing show elevated levels immediately prior to the event, but there is no increased risk after the event.

These results are derived from a large national panel survey, but the relative numbers of both events are small. A potential

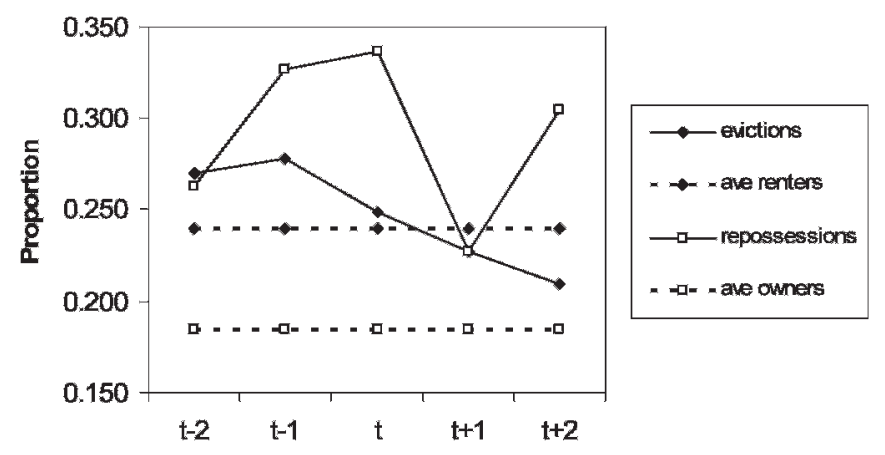

Figure 1 Proportion of those experiencing repossession or eviction with common mental illness.

\section{What is already known on this subject}

Housing tenure is associated with risk of common mental illness, but the effects of forced changes to housing tenure through repossession are not known.

\section{What this study adds}

This study suggests that housing repossession significantly increases the risk of common mental illness. Increasing numbers of housing repossessions are likely to lead to more people seeking help for mental health-related issues.

limitation is that those who have dropped out of the panel may be different from those who remain in the panel thus biasing the results, but the net effects were adjusted for major sociodemographic variables known to be associated with common mental illness. However, this cannot rule out the possibility that the declining mental health observed in the lead up to repossession makes the repossession more likely. The small number of events means that any interactions between variables cannot be explored, such as the double jeopardy of a marital breakdown and repossession/eviction occurring concurrently or close together. However, these data are unique in the UK and provide the only source of prospective information on those who experience repossession or eviction.

The social and economic processes leading to repossession and eviction are reasonably similar. ${ }^{9}$ However, the meanings of the events are likely to be different. Home ownership offers a heightened sense of ontological security compared to those in the more transitory rental sector..$^{23}$ This is reflected in the increased risk prior to repossession, whereas, in contrast, eviction from rented property shows a short peak before the event, which may be a product of the temporary reduction in ontological security, but quickly returns to normal as the individuals move into other housing. Although these results show a possible consequence of repossession or eviction processes, it is not known exactly what aspect, or aspects, affects psychological well-being. However, a rise in the number of repossessions is likely to result in more people seeking help for distress and anxiety; the two main dimensions of common mental illness as measured by the GHO.

Funding: This study was part of the scientific programme at the School of Health and Human Sciences at the University of Essex. No external funding.

Competing interests: None.

Ethics approval: University of Essex.

Provenance and peer review: Not commissioned; externally peer reviewed.

\section{REFERENCES}

1. Department of Communities and Local Government. Table 546: Housing market: repossessions, court actions for recovery of residential housing and land, England and Wales from 1989. 2007. www.communities.gov.uk/pub/144/ Table546Excel33Kb id1156144.xls (accessed 10 March 2008)

2. van Laere I, de Wit M, Klazinga N. Evaluation of the signalling and referral system for households at risk of eviction in Amsterdam. Health Soc Care Community 2009:17:1-8.

3. Stenberg SA, Kareholt I, Carroll E. The precariously housed and the risk of homelessness: a longitudinal-study of evictions in Sweden in the 1980s. Acta Sociol 1995; 38:151-65.

4. Connell MJO, Kasprow W, Rosenheck RA. Rates and risk factors for homelessness after successful housing in a sample of formerly homeless veterans. Psychiatr Serv 2008:59:268-75. 
5. Phinney R, Danziger S, Pollack HA, et al. Housing instability among current and former welfare recipients. Am J Public Health 2007;97:832-7.

6. Bartlett $\mathbf{S}$. The significance of relocation for chronically poor families in the USA. Environ Urban 1997:9:121-31.

7. Crane M, Warnes AM. Evictions and prolonged homelessness. Housing Stud 2000;15:757-73

8. Taylor MP, Pevalin DJ, Todd J. The psychological costs of unsustainable housing commitments. Psychol Med 2007;37:1027-36.

9. Böheim R, Taylor MP. My home was my castle: evictions and repossessions in Britain. J Hous Econ 2000:9:287-319.

10. Nettleton S, Burrows R. Mortgage debt, insecure home ownership and health: an exploratory analysis. Sociol Health IIIn 1998:20:731-53.

11. Cairney J, Boyle MH. Home ownership, mortgages and psychological distress. Housing Stud 2004;19:161-74.

12. Dunn JR. Housing and health inequalities: review and prospects for research. Housing Stud 2000;15:341-66.

13. Ellaway A, Macintyre S. Does housing tenure predict health in the UK because it exposes people to different levels of housing related hazards in the home or its surroundings? Health Place 1998;4:141-50.

14. Filakti H, Fox J. Differences in mortality by housing tenure and by car access. Population Trends 1995:81:27-30.
15. Taylor MF, Brice J, Buck N, Prentice-Lane E, eds. British Household Panel Survey User Manual Volume A: Introduction, Technical Report and Appendices. Colchester: University of Essex, 1998.

16. Lynn P, ed. Quality Profile: British Household Panel Survey Version 2.0: Waves 1 to 13: 1991-2003. Colchester: University of Essex, 2006.

17. Pevalin DJ, Goldberg DP. Social precursors to the onset and recovery from episodes of common mental illness. Psychol Med 2003:33:299-306.

18. Goldberg DP, Oldehinkel T, Ormel J. Why GHQ threshold varies from one place to another. Psychol Med 1998;28:915-21.

19. Pevalin DJ. Multiple applications of the GHQ-12 in a general population sample: an investigation of long-term retest effects. Soc Psychiatry Psychiatr Epidemiol 2000:35:508-12.

20. Goldberg DP, Williams P. A user's guide to the General Health Questionnaire. Windsor: NFER-Nelson, 1988

21. Allison PD. Fixed effects regression methods for longitudinal data using SAS. Cary, NC: SAS Press, 2005

22. Huber PJ. Robust statistics. New York: John Wiley, 1981

23. Shaw M. Housing and public health. Annu Rev Public Health 2004:25:397-418.

24. Padgett DK. There's no place like(a)home: ontological security among persons with serious mental illness in the United States. Soc Sci Med 2007:64:1925-36 